\title{
Increasing stringiness of low-fat mozzarella string cheese using polysaccharides
}

\author{
E. N. Oberg, ${ }^{* 1}$ C. J. Oberg, ${ }^{*} \dagger$ M. M. Motawee,§ S. Martini, ${ }^{*}$ and D. J. McMahon ${ }^{* 2}$ \\ *Western Dairy Center, Department of Nutrition, Dietetics, and Food Sciences, Utah State University, Logan 84322-8700 \\ †Department of Microbiology, Weber State University, Ogden, UT 84408-2506 \\ $\S N a t i o n a l$ Organization for Drug Control and Research, Giza, Egypt
}

\section{ABSTRACT}

When fat content of pasta filata cheese is lowered, a loss of fibrous texture occurs and low-fat (LF) mozzarella cheese loses stringiness, making it unsuitable for the manufacture of string cheese. We investigated the use of various polysaccharides that could act as fat mimetics during the stretching and extruding process to aid in protein strand formation and increase stringiness. Low-fat mozzarella cheese curd was made, salted, and then $3.6-\mathrm{kg}$ batches were heated in hot $\left(80^{\circ}\right) 5 \%$ brine, stretched, and formed into a homogeneous mass. Hot $\left(80^{\circ} \mathrm{C}\right)$ slurries of various polysaccharides were then mixed with the hot cheese and formed into LF string cheese using a small piston-driven extruder. Polysaccharides used included waxy corn starch, waxy rice starch, instant tapioca starch, polydextrose, xanthan gum, and guar gum. Adding starch slurries increased cheese moisture content by up to $1.6 \%$ but was not effective at increasing stringiness. Xanthan gum functioned best as a fat mimetic and produced LF string cheese that most closely visually resembled commercial string cheese made using low-moisture part skim (LMPS) mozzarella cheese without any increase in moisture content. Extent of stringiness was determined by pulling apart the cheese longitudinally and observing size, length, and appearance of individual cheese strings. Hardness was determined using a modified Warner-Bratzler shear test. When LF string cheese was made using a $10 \%$ xanthan gum slurry added at $\sim 1 \%$, increased consumer flavor liking was observed, with scores after 2 wk of storage of 6.44 and 6.24 compared with 5.89 for the LF control cheese; although this was lower than an LMPS string cheese that scored 7.27. The 2-wk-old LF string cheeses containing xanthan gum were considered still slightly too firm using a just-about-right (JAR) test, whereas the LMPS string cheese was considered as JAR

Received August 11, 2014.

Accepted March 30, 2015.

${ }^{1}$ Current address: Leprino Foods Company, PO Box 173400, Denver, CO 80217.

${ }^{2}$ Corresponding author: donald.mcmahon@usu.edu for texture. With further storage up to $8 \mathrm{wk}$, all of the LF string cheeses softened (JAR score was closer to 3.0); however, much of the stringiness of the LF string cheeses was also lost during storage. We have demonstrated the potential feasibility of increasing stringiness in LF string cheese using polysaccharides with xanthan gum, although further research is needed to develop quantitative methodology for measuring stringiness and to maintain stringiness through the extended refrigerated shelf life needed for string cheese.

Key words: mozzarella, string, starch, xanthan

\section{INTRODUCTION}

Low-moisture part skim (LMPS) mozzarella string cheese is considered a snack cheese that is eaten cold rather than consumed hot on foods such as pizza. String cheese sales continue to grow in terms of dollars and units (Mayer, 2011), as it is a popular snack among children and is increasing in popularity among adults. With a shift in snack foods to lower calories and lower fat options, a low-fat ( $\mathbf{L F}$ ) alternative for mozzarella string cheese may help continue to increase sales and prove health benefits to consumers (Duboc and Mollet, 2001).

During the heating and stretching stage of mozzarella cheese manufacture, fat globules form channels between the protein strands and allow protein fibers to align and separate, giving mozzarella cheese its stringiness (Oberg et al., 1993). This stringiness is extenuated during manufacture of string cheese as the hot cheese is extruded through a long, narrow die that further aligns the protein fibers parallel to each other. This allows the characteristic thin strings of cheese (Figure 1) to be easily peeled from sticks of string cheese (Taneya et al., 1992). Removing fat from mozzarella cheese decreases fiber formation because the protein strands fuse together during stretching and extruding, resulting in increased protein-protein interactions that leads to a loss of strand formation or stringiness (Mulvaney et al., 1997). Given that stringiness is an important consumer expectation of mozzarella string cheese, a new way of 


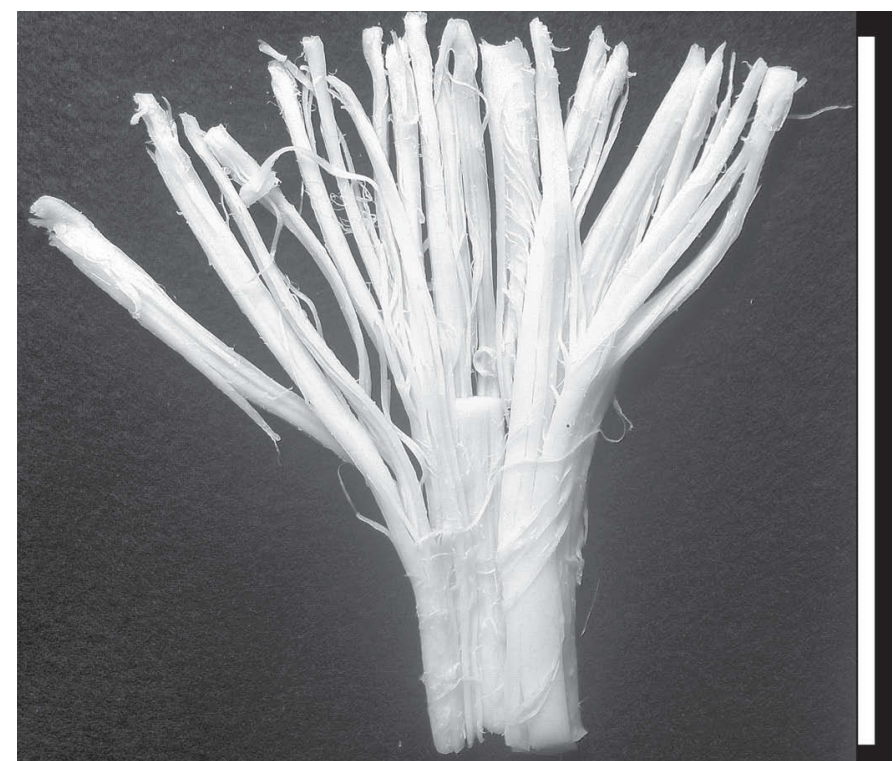

Figure 1. Characteristic thin strings of cheese pulled from a stick of low-moisture part-skim mozzarella string cheese; bar $=10 \mathrm{~cm}$.

causing fiber formation to generate stringiness is needed when lowering fat content. Along with stringiness, a low-fat string cheese should have similar hardness to LMPS mozzarella cheese and not be translucent in appearance. A common undesirable characteristic of LF cheeses is a loss of whiteness when the cheese is cold. This can be overcome by adding a low level of titanium dioxide to the milk before cheesemaking (Kosikowski and Brown, 1969; Wadhwani and McMahon, 2012).

Fat, moisture, and calcium concentration all affect the functionality of mozzarella cheese. Lowering calcium content of LF mozzarella cheese allows for increased moisture content and a cheese that is softer and has increased melting (Joshi et al., 2004; McMahon et al., 2005). Preacidification of milk before renneting is the most effective way to lower calcium content of lowerfat mozzarella cheese and improve physical properties (Merrill et al., 1994) and postmelt chewiness (Metzger et al., 2001). Modifying calcium in lower-fat cheese can also be achieved by adding a chelating agent, such as trisodium citrate, to cheese curd during salting (Mizuno and Lucey, 2005).

Fat replacers have been used to improve the texture of lower-fat cheeses, and their effectiveness appears to be related to particle size and distribution of the fat replacer throughout the protein matrix (McMahon et al., 1996). Whereas such fat replacers can increase the moisture content of lower-fat cheese, their addition has generally not provided any improvement on the melting properties of mozzarella cheese. Whether the fat replacer has the ability to mimic the functioning of milkfat droplets by interrupting the extensive proteinprotein interactions that can occur in the cheese matrix of lower fat cheeses will determine its effectiveness (McMahon et al., 1996; Mistry, 2001; Rogers et al., 2010).

For most natural cheeses, the only opportunity to add a fat mimetic is before renneting of milk. For pasta filata cheeses, such as mozzarella, it has been shown that additional ingredients, such as starches, can also be added during or after the heating or stretching process (Barz and Cremer, 1996). Our objective was to determine if stringiness could be restored to a LF mozzarella string cheese by adding a polysaccharide material to a hot mass of cooked or stretched LF mozzarella cheese. The polysaccharide could then mimic fat by interrupting protein-protein interactions. Such an LF string cheese would then have a fibrous structure with parallel proteins strands that could be peeled lengthwise from the stick of LF cheese, giving it the stringiness expected for a mozzarella string cheese. We performed preliminary experiments to screen a variety of polysaccharides being added to the hot LF cheese mass and then more extensive testing using xanthan gum.

\section{MATERIALS AND METHODS}

\section{Polysaccharides}

Waxy rice starch, waxy corn starch, and instant tapioca starch were obtained from National Food Starch (Bridgewater, NJ) and selected based on previous use in milk coagulation studies (Brown et al., 2012). Xanthan gum (Grindsted Xanthan 80), guar gum, and polydextrose were obtained from Danisco (Madison, WI). Each polysaccharide was hydrated into a slurry using distilled water, stirred until dissolved, and then gently heated to achieve a homogeneous consistency. Starches were prepared as $10 \%$ (wt/wt) slurries, polydextrose as a $50 \%$ (wt/vol) slurry, and gums as $2 \%$ (wt/wt) slurries.

The first screening trial involved the 3 starches using a single batch of LF cheese, then a second batch of cheese was made to screen the various gums along with instant tapioca starch. In the final testing using xanthan gum, duplicate batches of LF cheese were manufactured.

\section{Cheese Manufacture}

Pasteurized $0.7 \%$ fat milk (273 kg) was obtained from the Aggie Creamery (Utah State University, Logan, UT) and made into cheese curd following the procedure of Merrill et al. (1994) with several modifications. A combination of $28 \mathrm{~g}$ of $\mathrm{TiO}_{2}$ paste (Roha USA LLC, St. Louis, MO) diluted 1:10 in water and $1 \mathrm{~mL}$ of an- 
natto (DSM Food Specialties USA Inc., Eagleville, PA) diluted 1:20 in water was added to the cold milk to improve opaqueness of the subsequent LF cheese. Milk was preacidified with $5 \%$ (wt/wt) acetic acid to $\mathrm{pH} 6.3$, warmed to $34^{\circ} \mathrm{C}$, and inoculated with $48 \mathrm{~g}$ of Streptococcus thermophilus TS-20D starter culture (DSM Food Specialties USA Inc.). After $30 \mathrm{~min}, 24 \mathrm{~mL}$ of doublestrength chymosin (Maxiren; DSM Food Specialties USA Inc.; 650 international milk clotting units $/ \mathrm{mL}$ ) was added and the curd was cut after $25 \mathrm{~min}$. Stirring of the curd was stirred with temperature maintained at $34^{\circ} \mathrm{C}$ until curd $\mathrm{pH}$ reached 6.1 and two-thirds of the whey was removed. Stirring continued until curd reached $\mathrm{pH} 5.25$, then the whey was drained and the curd was washed with sufficient cold water to lower curd temperature to $15^{\circ} \mathrm{C}$ to stop further acid production by the starter culture. After subsequent draining, salt was added to the curd at a rate of $10 \mathrm{~g} / \mathrm{kg}$ of curd, then the curd was divided into $3.6-\mathrm{kg}$ batches.

Curd was hand-stretched in $5 \% \mathrm{NaCl}$ (wt/wt) hot brine $\left(80^{\circ} \mathrm{C}\right)$ and formed into a homogeneous mass.
Then, hot cheese was mixed in a small vat with the hot polysaccharide slurry at the required level and kneaded by hand to produce a homogeneous mass of LF cheese. Level of polysaccharide slurry addition to the cheese mass was $8 \%$ (wt/wt) for starches, $10 \%$ for polydextrose, and $0.25,0.5,1.0,1.5$, and $2.0 \%$ for gums. The hot LF cheese mixture was then placed into a small piston-driven heat-jacketed extruder (Figure 1), forced through a 1.6-cm-diameter die to form the string cheese, and cut manually into $\sim 15$-cm lengths (Figure 2 ). The cheese was put into an ice brine solution $\left(0^{\circ} \mathrm{C}\right)$ of $5 \%$ $\mathrm{NaCl}$ (wt/wt) for $10 \mathrm{~min}$. Each lot of string cheese was stored in vacuum-sealed packaging at $6^{\circ} \mathrm{C}$.

\section{Chemical Analysis}

Chemical analysis of cheeses was performed after 1 wk of storage. Cheeses were analyzed for fat using the Babcock method (method 15.083; Wehr and Frank, 2004) and salt using a chloride analyzer (Wadhwani and McMahon, 2012). The $\mathrm{pH}$ was measured using a
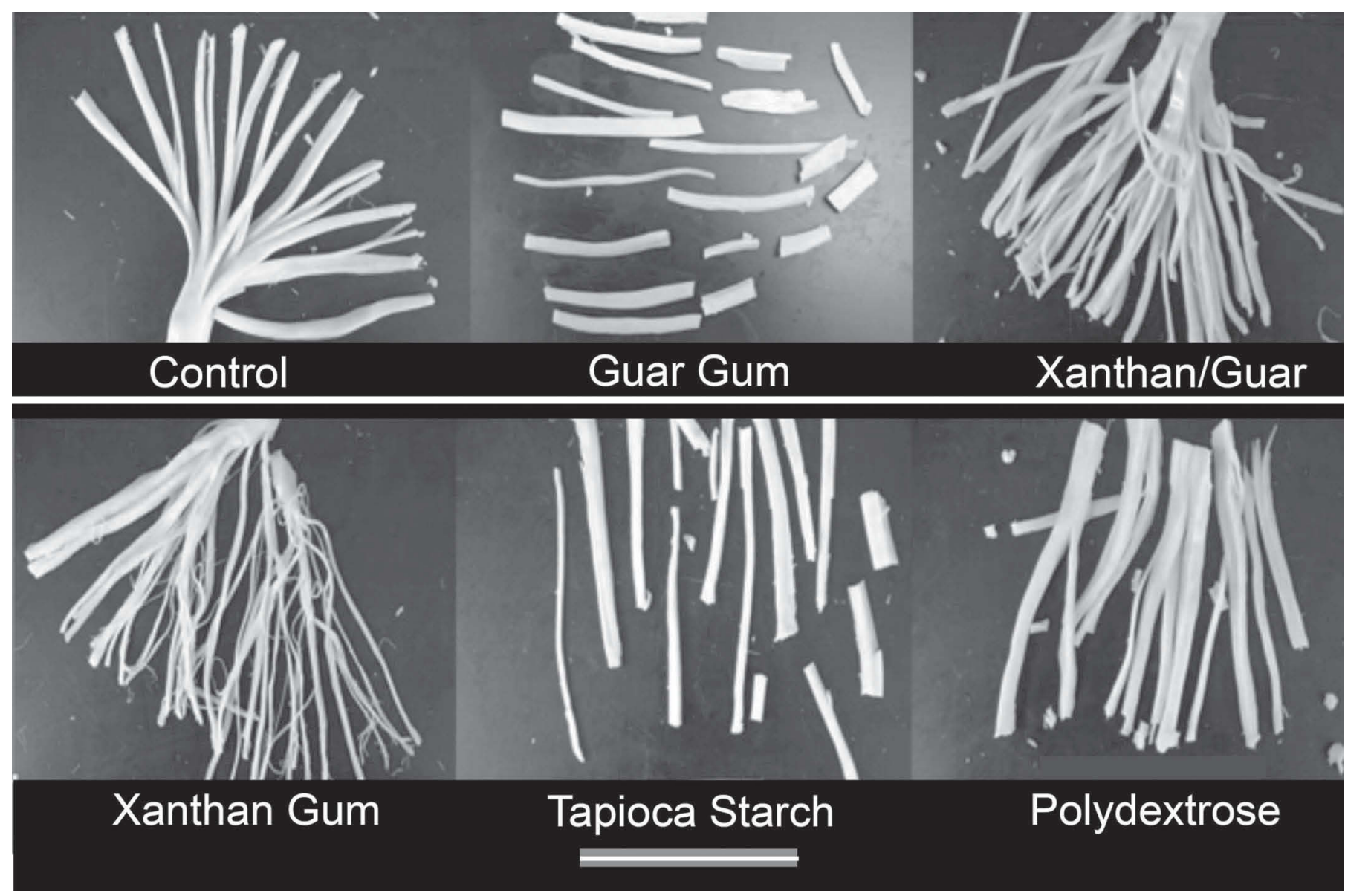

Figure 2. Stringiness assessment of 4-wk-old low-fat mozzarella cheese made with addition of various polysaccharide slurries compared with a control low-fat string cheese; bar $=10 \mathrm{~cm}$. 
glass electrode after diluting $5 \mathrm{~g}$ of shredded cheese in $20 \mathrm{~mL}$ of distilled water and stomaching for $1 \mathrm{~min}$ at $260 \mathrm{rpm}$. Moisture content was determined in triplicate by weight loss using a microwave oven (CEM Corp., Indian Trail, NC) at 100\% power with an endpoint setting of $<0.4 \mathrm{mg}$ of weight change over $2 \mathrm{~s}$. Differences between the moisture content of LF cheeses made using starch and the control LF cheese were analyzed using a one-tailed $t$-test, and composition of cheeses made using various levels of xanthan gum was analyzed by one-way ANOVA using StatPlus:mac2009 (AnalystSoft Inc., Alexandria, VA)

\section{Stringiness}

Stringiness was evaluated by visual observation of strings that could be pulled from the 15-cm long string cheeses longitudinally by hand (Taneya et al., 1992). Cheeses that produced strings with smaller diameters and greater lengths were considered to have more stringiness.

\section{Hardness}

Hardness was measured using a shear test to simulate a person biting into the cheese by measuring resistive load (Bhaskaracharya and Shah, 1999) with modifications from a beef rib steak shear test (Caine et al., 2003). A Warner-Bratzler blade with a $3-\mathrm{mm}$ round edge mounted on a TA.XT Plus Texture Analyzer (Texture Technologies, Scarsdale, NY) was lowered into the cheese perpendicular to the strings (i.e., crosssection orientation) at $1 \mathrm{~mm} / \mathrm{s}$ and load was measured over time. Results were plotted as load-versus-distance plots.

\section{Microstructure}

Distribution of polysaccharides in the cheese matrix was observed using laser scanning confocal microscopy according to McManus et al. (2009). Cheese samples were frozen using liquid nitrogen and thin slices $(1 \times 1$ $\times 0.5 \mathrm{~mm}$ ) were cut perpendicular to the protein fibers using a microtome cryostat (International Equipment Company, Needham Heights, MA). Slices were fixed for $18 \mathrm{~h}$ (in a fume hood) by immersing in osmium tetroxide vapor in an enclosed Petri dish containing filter paper soaked in an osmium tetroxide solution. Fixed cheese slices were treated with $0.5 \%$ (wt/vol) periodic acid for $20 \mathrm{~min}$ to oxidize polysaccharides and then washed with several exchanges of deionized water. Washed samples were immersed in a $0.1 \%$ (wt/vol) acriflavin $\mathrm{HCl}$ solution while being microwaved (model 3470, Ted Pella Inc., Redding, CA) under a vacuum for
4 cycles of 2 min on and 2 min off at $31^{\circ} \mathrm{C}$ to attach the fluorophore to aldehyde groups of the polysaccharides. Samples were then immersed in $0.1 \%$ (wt/vol) Rhodamine B and microwaved under a vacuum, as previously described. The cheese samples were washed with deionized water, mounted on a glass slide and covered in glycerol or gelatin solution, then covered with a glass coverslip carefully so as to not trap any air bubbles under the coverslip.

Samples were imaged on a laser scanning confocal microscope (MRC 23; Bio-Rad Laboratories Inc., Hercules, CA) with a $\mathrm{Kr} /$ Ar laser exciting the acriflavin at $488 \mathrm{~nm}$ and the Rhodamine B at $568 \mathrm{~nm}$. Sample emissions were from 488 to 650 and 550 to $750 \mathrm{~nm}$, respectively, using exclusion filters of 512 to 532 and $>585$ $\mathrm{nm}$. Images were false colored with protein (Rhodamine B fluorescence) as gray and polysaccharide (acriflavin fluorescence) as white.

\section{Sensory}

After 2 and 8 wk of storage time, consumer sensory panels were conducted at the Utah State University Food Sensory Laboratory using panels of 80 to 100 volunteers from the community. Commercial LMPS mozzarella string cheeses were purchased randomly from a local supermarket the day before the test. Each panelist was presented with $1.5-\mathrm{cm}$ long samples of cheese at room temperature $\left(\sim 22^{\circ} \mathrm{C}\right)$ in randomized order and asked to evaluate (1) overall liking based on flavor using on a 9-point Hedonic scale in which $9=$ like extremely, $8=$ like very much, $7=$ like moderately, $6=$ like slightly, $5=$ neither like nor dislike, $4=$ dislike slightly, $3=$ dislike moderately, $2=$ dislike very much, 1 = dislike extremely; and (2) texture using a 5-point just-about-right (JAR) scale with options of just right, too firm $(>3)$, or too soft $(<3)$. Panelist responses were recorded using Sims2000 software (Sensory Computer Systems, Morristown, NJ). Hedonic ratings were analyzed using one-way ANOVA with treatments as fixed effects and consumers as random effects. All statistical analysis and JAR histograms were obtained using GraphPad Prism for Windows version 6.01 (GraphPad Software Inc., La Jolla, CA).

\section{RESULTS AND DISCUSSION}

Mean $( \pm \mathrm{SD})$ composition of LF string cheeses made with or without starch was $59.2 \%( \pm 0.7)$ moisture, $6 \%$ fat, $1.97 \%( \pm 0.21)$ salt, and $\mathrm{pH} 5.21( \pm 0.06)$. Adding a starch had a tendency $(P=0.06)$ to increase moisture by an average of $1.0 \%$. Based on solids content of the starch and the LF cheese, a theoretical 1.5\% increase in moisture should occur, although the additional work- 
ing of the hot curd with the hot starch slurry may have counteracted this with increased loss of moisture. That the LF string cheeses had higher moisture content than $51 \%$ (i.e., moisture of a commercial LMPS mozzarella string cheese) was expected. Manufacturing steps (preacidification of milk to $\mathrm{pH} 6.3$, elimination of the curd cook step, and washing the curd with $10^{\circ} \mathrm{C}$ water) that were used to make the LF string cheese had previously been shown to be effective in increasing moisture content of lower-fat mozzarella cheese (Merrill et al., 1994). Even though the LF string cheeses had only $6 \%$ fat, the high moisture content was sufficient so that they were not hard and rubbery. Of the 3 starches used (waxy rice starch, waxy corn starch, and instant tapioca starch) only the cheese made using instant tapioca starch had adequate stringiness upon visually examining stringiness after $2 \mathrm{wk}$ of storage (long strings and small diameter); this cheese was used in subsequent comparison with other polysaccharides.

In a second trial, LF mozzarella cheeses made with instant tapioca starch, polydextrose, guar gum, xanthan gum, or a xanthan and guar gum mixture were not different in composition to a control LF string cheese without any polysaccharide addition. Mean $( \pm \mathrm{SD})$ composition was $60.9 \%( \pm 0.8)$, moisture, $6 \%$ fat, $1.74 \%( \pm 0.29)$ salt, and pH $5.42( \pm 0.10)$. Cheeses made with xanthan gum slurries had similar moisture to the control cheese, which was expected as only $2 \%$ (wt/wt) or less slurry was added. Cheese made with instant tapioca starch had higher moisture than the LF control, and using this as a duplicate with the first screening test showed an average $1.6 \%$ moisture increase $(P=0.038)$.

String formation of the LF string cheeses after $4 \mathrm{wk}$ of storage is shown in Figure 2. The control LF string cheese with no added polysaccharide exhibited very little string formation and only thick strands could be pulled from cheese stick. Adding polydextrose, tapioca starch, or guar gum did not improve string formation. These cheeses were similar to the control LF string cheese and cheese strands would often break rather than extend the whole length of the cheese stick. Lowfat cheeses made with either xanthan gum or a combination of guar gum with xanthan gum, produced fine strings with the smallest diameter and greatest length. With further storage, in general, the stringiness of the LF string cheeses decreased, with strings becoming shorter and thicker. At 8 wk of storage, cheeses containing xanthan gum continued to have some stringiness whereas strands pulled from the control LF string cheese fractured.

When commercial LMPS string cheese sticks were examined using the compression or penetration test at a perpendicular angle to the direction of string formation in the cheese as it was extruded, it was observed that the cheese initially deformed slightly with the resistive load increasing in a linear manner with penetration of the probe into the cheese. This can be related to the reinforcing effect that fat globules have on a cheese matrix structure (Rogers et al., 2010). Then, after 50 to $70 \%$ ( 8 to $11 \mathrm{~mm}$ ) of penetration, the cheeses would partially fracture but maintained similar resistive load (Figure 3). This was expected for a cheese containing $\sim 20 \%$ fat distributed in serum channels between strands of protein that could act as weak points in the overall cheese matrix, allowing stress to be easily dissipated as the internal strands of protein in the string cheese are compressed and then fracture. In contrast, the LF string cheeses exhibited a more elastic compression and a brittle fracture through the bulk of the cheese at 75 to $85 \%$ (12 to $14 \mathrm{~mm}$ ) compression. This was seen in an exponential increase in load with increasing penetration followed by a sharp release of stress at fracture (Figure 4).

The mixing of the hot mass of cheese with the hot polysaccharide slurries did appear to simulate the role of the fat droplets in promoting string formation by the protein fibers, but had less effect on reducing elasticity. When the LF string cheeses were examined using confocal microscopy it was observed that the polysaccharides were distributed throughout the cheese matrix (Figure 5) in a similar way to fat in LMPS mozzarella cheese (Oberg et al., 1993).

As LF string cheeses made with added xanthan gum produced longer strings with smaller diameters when compared with the other LF string cheeses, we made LF cheese with 0.25 to $2.0 \%$ (wt/wt) of xanthan gum slurry added to the hot mass of cheese. No significant difference $(P \geq 0.8)$ in composition was found between the control and xanthan gum containing LF string cheeses and mean $( \pm \mathrm{SD})$ composition was $60.6 \%$ $( \pm 0.4)$ moisture, $6 \%$ fat, $1.85 \%( \pm 0.08)$ salt, and $\mathrm{pH}$ $5.46( \pm 0.06)$.

As shown in Figure 6, after 2 wk of storage, thin long strings could be pulled from all of the LF cheeses that contained xanthan gum, whereas mainly thicker strands could be pulled from the control LF cheese. Our observation from handling the cheeses was that the LF cheeses with xanthan gum slurry added at 0.5 to $1.0 \%$ had slightly better string formation, with strings with smaller diameters more easily pulled from the cheese stick. However, during further storage, string formation diminished in all of the LF cheeses whether xanthan gum was added or not (Figure 7). The ability of the xanthan gum to prevent knitting of the protein strands was apparently lost and only thick strands that easily fractured could be pulled from the LF cheese sticks. The cheeses with $1.0 \%$ added xanthan gum slurry 

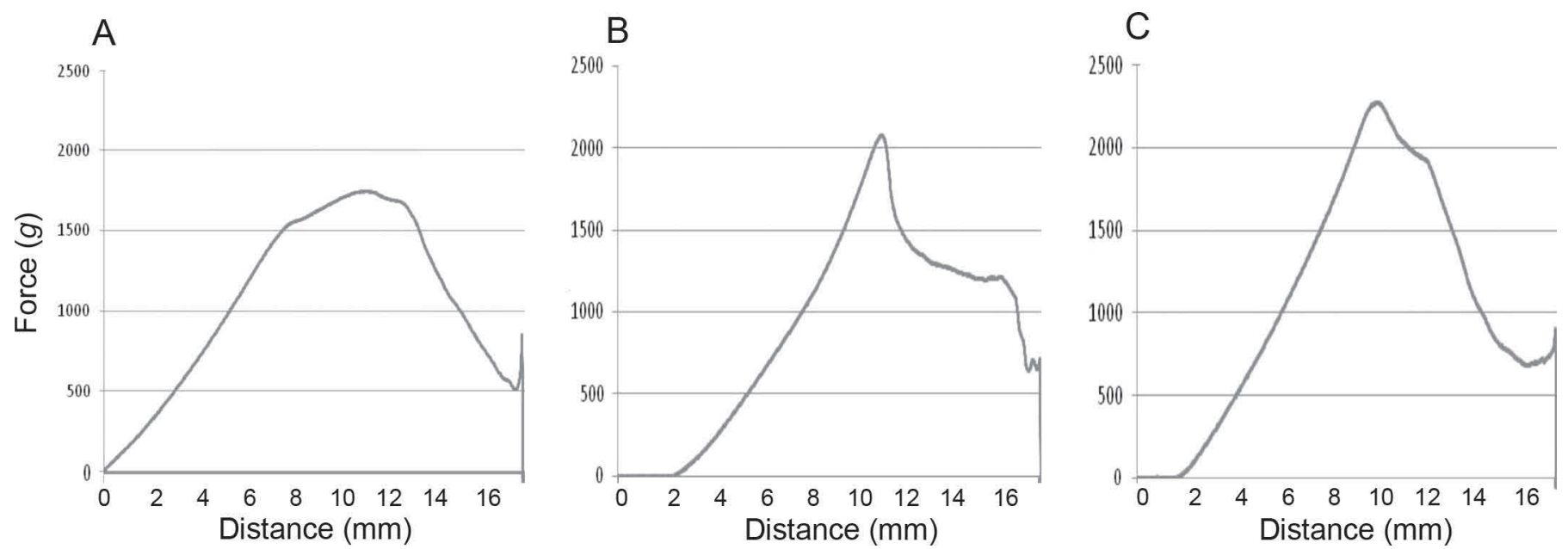

Figure 3. Load-versus-distance curves from the shear test of 3 different brands (A, B, C) of low-moisture part-skim mozzarella string cheeses.

produced the thinnest long strings, whereas the string cheese with $2.0 \%$ added xanthan had little to no string formation after 8 wk of storage.

Low-fat string cheeses at 2 wk of storage were hard and rubbery with stress at fracture ranging from 10,000 to 20,000 g-force (Figure 8). Texture was improved by adding the xanthan gum slurry when comparing the depth of penetration at which the cheese fractured. Typically, an LMPS string cheese would deform and collapse under the force of the blade and fracture between 8 and $11 \mathrm{~mm}$ penetration. The control LF string cheese at 2 wk of storage time was more rubbery and exhibited a brittle fracture after $\sim 15 \mathrm{~mm}$ penetration, whereas those containing xanthan gum slurry fractured sooner at $\sim 12 \mathrm{~mm}$ penetration. After 8 wk of storage, the LF string cheeses were softer (stress at fracture was 2,000 to $3,000 \mathrm{~g}$-force) and fracture was less complete (Figure 9).
This softening and loss of stringiness of the LF string cheeses during storage needs to be resolved, as the cheese needs to have a longer shelf life to be viable commercially. It may be that although the polysaccharide slurries act to form channels and concomitantly promote formation of strands of protein material between them, that over time the moisture contained within the slurries is absorbed into the protein matrix and the channels are subsequently lost. Or it may be that fusion occurs between the polysaccharides and protein matrix so that the weak polysaccharide channels that initially allowed protein fibers to be pulled from body of the cheese no longer exist. This loss of stringiness by the experimental LF string cheeses may have been enhanced as the cheeses were vacuum packed after manufacture to prevent mold growth and the package may have exerted too high a pressure on the cheese. Loss of stringiness may be less of a problem if gas flushing is
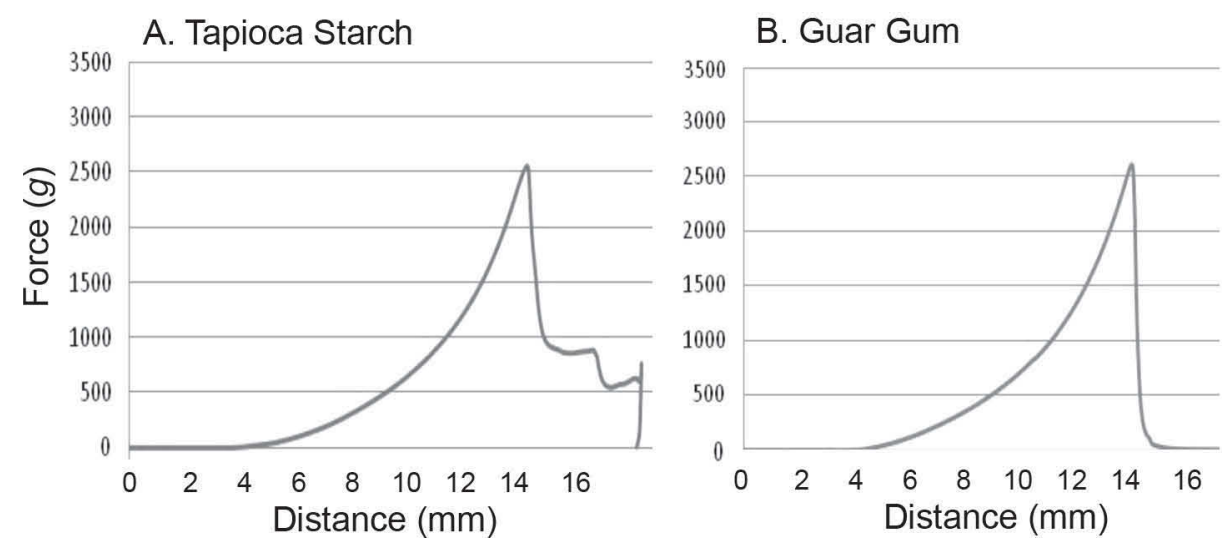

\section{Xanthan Gum}

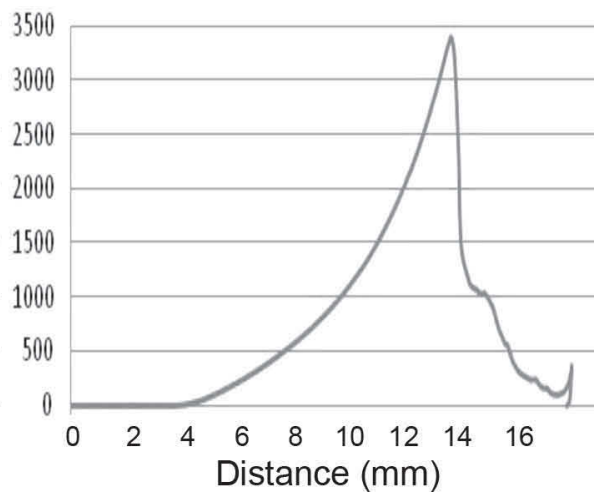

Figure 4. Load-versus-distance curves from the shear test of low-fat string cheese with addition of slurries of (A) instant tapioca starch, (B) guar gum, and (C) xanthan gum. 

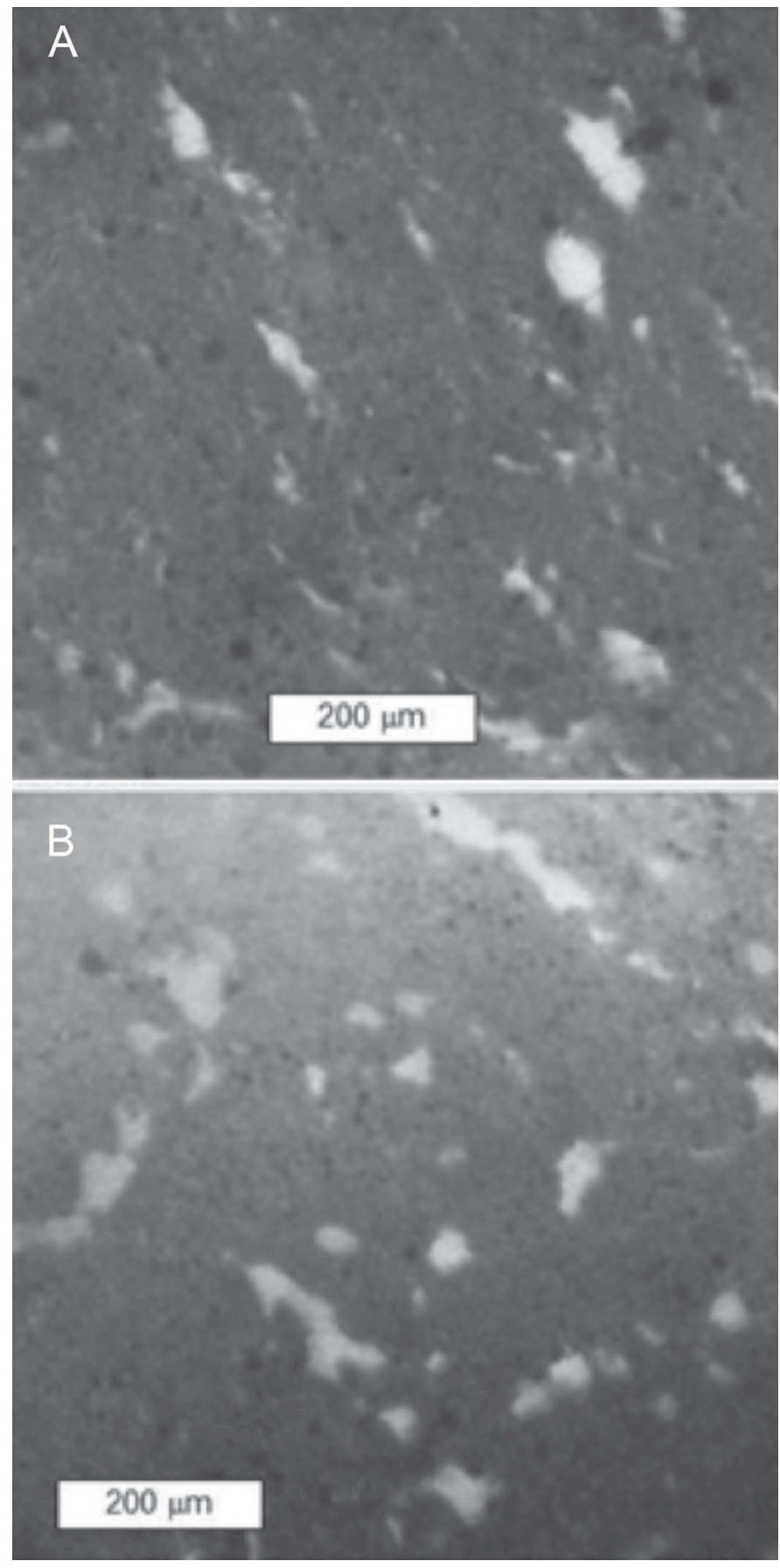

Figure 5. Microstructure of low-fat mozzarella string cheese sectioned perpendicular to string direction containing (A) instant tapioca starch and (B) polydextrose. The presence of polysaccharide (white) was visualized by fluorescence from acriflavin and protein (gray) by Rhodamine B, whereas fat (black) was shown by lack of fluorescence.

used during packaging. Further research is needed to understand the interactions between the proteins and the polysaccharides especially during storage of string cheese.
Significant $(P<0.01)$ differences were noted in both consumer sensory flavor liking and JAR texture scores among the cheeses when tested at both 2 and 8 wk. Among the LF string cheeses, the LF string cheese made with $1 \%$ added xanthan gum slurry had the highest liking (Figure 10). Although the flavor liking for the cheese made using $1 \%$ added xanthan gum slurry was not significantly different from the commercial LMPS cheese, this may have been because of variations in samples of commercial string cheese, as their flavor liking scores varied from 6.2 to 7.3. When comparing texture, $64 \%$ of consumers rated the LMPS cheese as being JAR, with some rating it firmer than JAR $(24 \%)$ and some as softer than JAR (12\%). In contrast, consumer rating of the LF control string cheese was skewed toward being too firm and only $9 \%$ rated it as being JAR (Figure 11). Addition of xanthan gum slurry resulted in more consumers rating the LF string cheeses as being JAR, up to $42 \%$ when $1 \%$ xanthan gum slurry was added, although it was still skewed toward being slightly too firm (53\% of panelists).

After $8 \mathrm{wk}$ of storage, the flavor scores for the LF cheeses with 0.5 to $1.5 \%$ xanthan were not significantly different (mean score $=6.06)$ compared with the LMPS string cheese (mean score $=6.43$ ). Some improvement in texture was observed, with the LF cheeses becoming softer but still having a lower percentage of consumers (47\%) scoring them as having a JAR texture compared with $72 \%$ of consumers judging the LMPS cheese as JAR (mean JAR score of 3.0). In comparison, the LF cheese had a JAR score of 3.35 , which is only slightly less than the 2 -wk score of 3.63, but the difference was that at 2 wk no one scored the cheese as being too soft whereas at $8 \mathrm{wk} 12 \%$ scored it as too soft. This increased to $30 \%$ for the LF cheese with $1.5 \%$ xanthan gum slurry.

Overall, issues persisted with the firmness of the LF cheeses, and considering that they only contain $6 \%$ fat, the flavor liking scores were not that much lower than the LMPS string cheeses and still in the slightly like category (Figure 10). Compared with the control LF cheese, adding a xanthan gum slurry to the hot LF cheese mass before extrusion did make it much easier to peel off full-length, thin strings of cheese. However, as LF cheeses with added xanthan slurry were stored it became more difficult to peel off strings and they became more similar to the control LF cheese (Figure 6 ). This began to be noticeable after $4 \mathrm{wk}$ of aging and quite apparent by 8 wk.

Xanthan gum is a high-molecular-weight heteropolysaccharide with a cellulose skeleton and trisaccharide side chains of D-mannose and D-glucuronic acid on the glucose residues. Many of the properties of xanthan gum are the result of its double helical conformation 

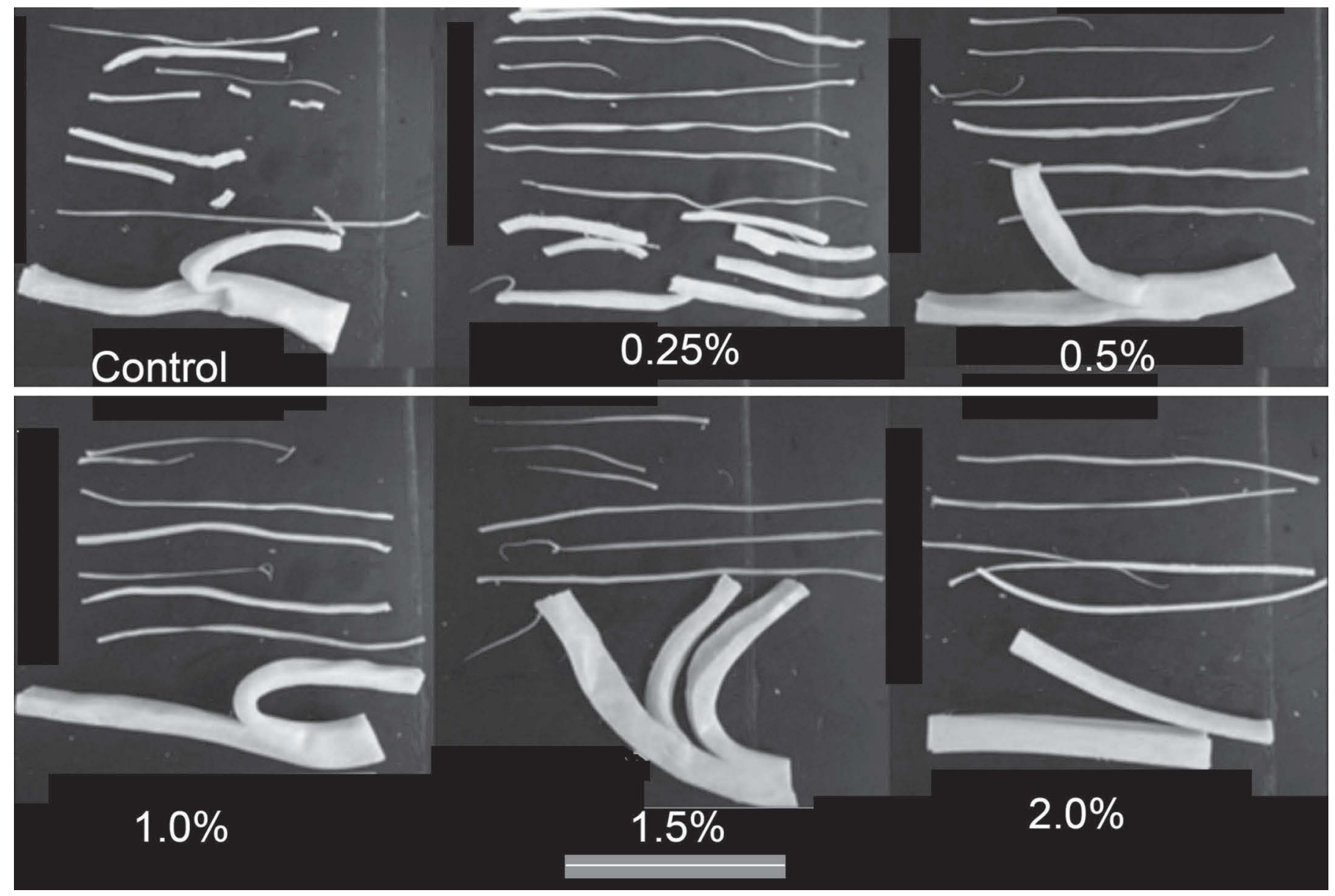

Figure 6. Stringiness assessment of 2-wk-old control low-fat mozzarella cheese and cheeses made with addition $0.25,0.5,1.0,1.5$, and $2.0 \%$ xanthan gum slurry; bar $=10 \mathrm{~cm}$.

when in solution, as the trisaccharide side chains stabilize the conformation (Ricciardi and Clementi, 2000). Charges on the polysaccharides also play a role in how well they mimic fat droplets during the pasta filata and extruding process as their charge affects how they interact with the protein matrix. Linear neutral polysaccharides contribute to viscosity but not to elasticity, whereas negatively charged polysaccharides contribute to elasticity but not viscosity of cheese systems (Duboc and Mollet, 2001). How the polysaccharides interaction with the positively charged $\mathrm{CN}$ particles will determine whether the polysaccharide reinforces the strength of the protein network or creates the interruptions and weak areas needed for forming protein strands that can be peeled off or away from the cheese mass. To function as a fat mimetic during the cooker or stretcher phase of string cheese production, the material must inhibit complete fusion of the para-CN network (Corredig et al., 2011). This suggests that the better performance by the xanthan gum slurry in promoting stringiness in
LF string cheese was because it both physically blocked coalescence of the protein matrix and did not interact chemically with the proteins during the mixing and extrusion of the hot cheese.

\section{CONCLUSIONS}

Low-fat mozzarella string cheeses were manufactured by mixing hot slurries of various polysaccharides with hot cheese from the cooker or stretcher. Visual improvements in string formation were observed in the extruded cheese depending on type of polysaccharide. It was possible to pull thin strings from some of the LF string cheeses after 2 wk of storage, although we were not able to obtain a quantitative measure of stringiness. Based on our observations, LF string cheese made using a xanthan gum slurry was more easily pulled apart to form thin strings (or strands) of cheese and was therefore considered to have better stringiness than LF string cheeses made using starch or polydextrose. When only a 


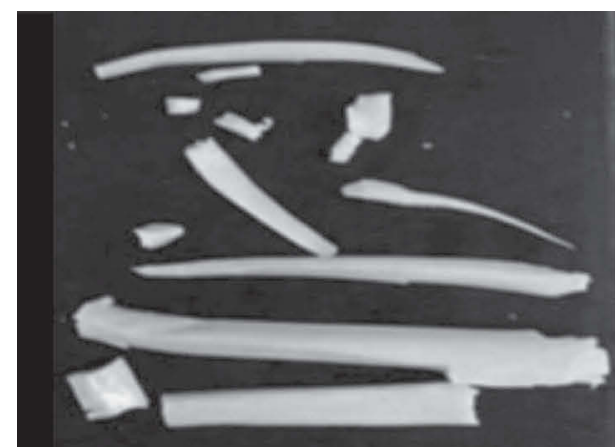

Control

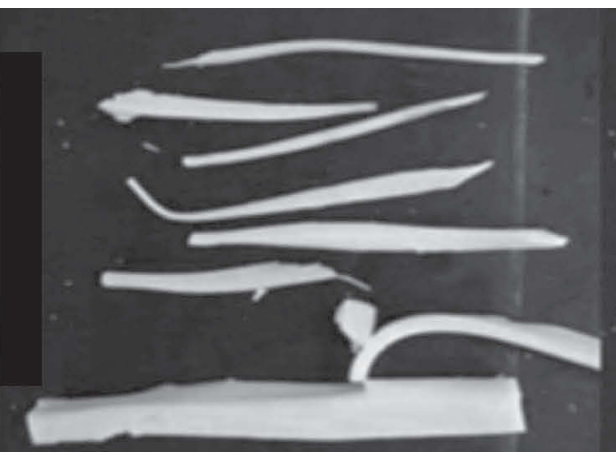

$0.25 \%$

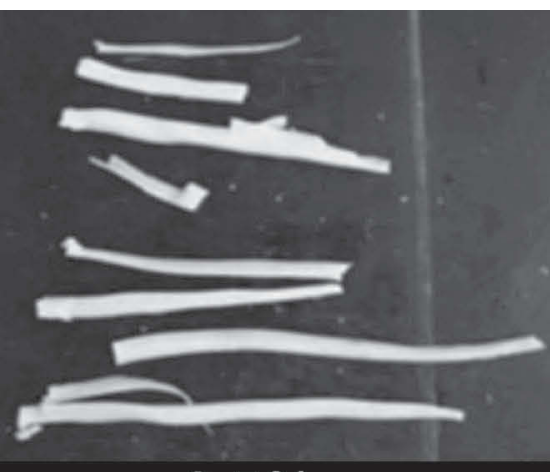

$0.5 \%$

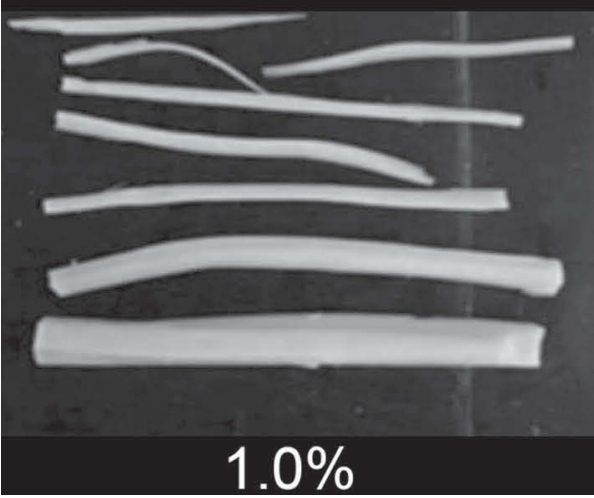

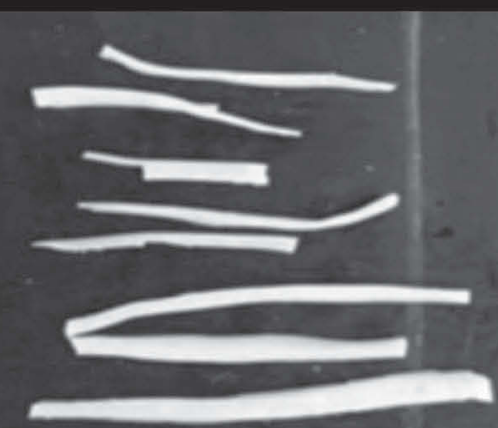

$1.5 \%$

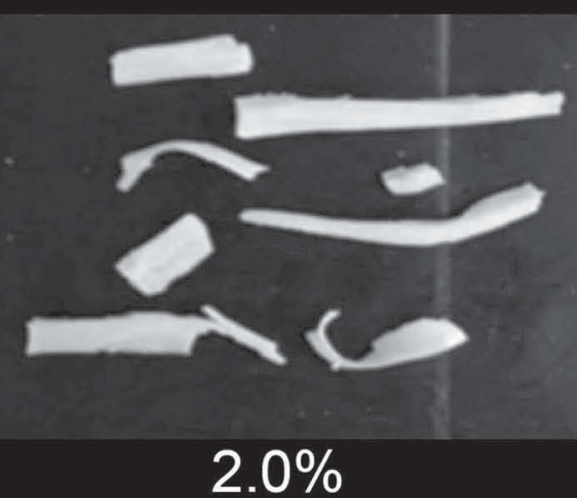

Figure 7. Stringiness assessment of 8-wk-old control low-fat mozzarella cheese and cheeses made with addition $0.25,0.5,1.0,1.5$, and $2.0 \%$ xanthan gum slurry; bar $=10 \mathrm{~cm}$.

low amount (e.g., $\sim 1 \%$ xanthan gum slurry) was added, no change in moisture, $\mathrm{pH}$, or salt content was noted, whereas moisture increased up to $1.6 \%$ when adding
$8 \%$ of a $10 \%$ (wt/wt) starch slurry. Based on consumer sensory evaluation, incorporation of a $1 \%$ xanthan gum slurry into LF cheese has potential for manufacture of
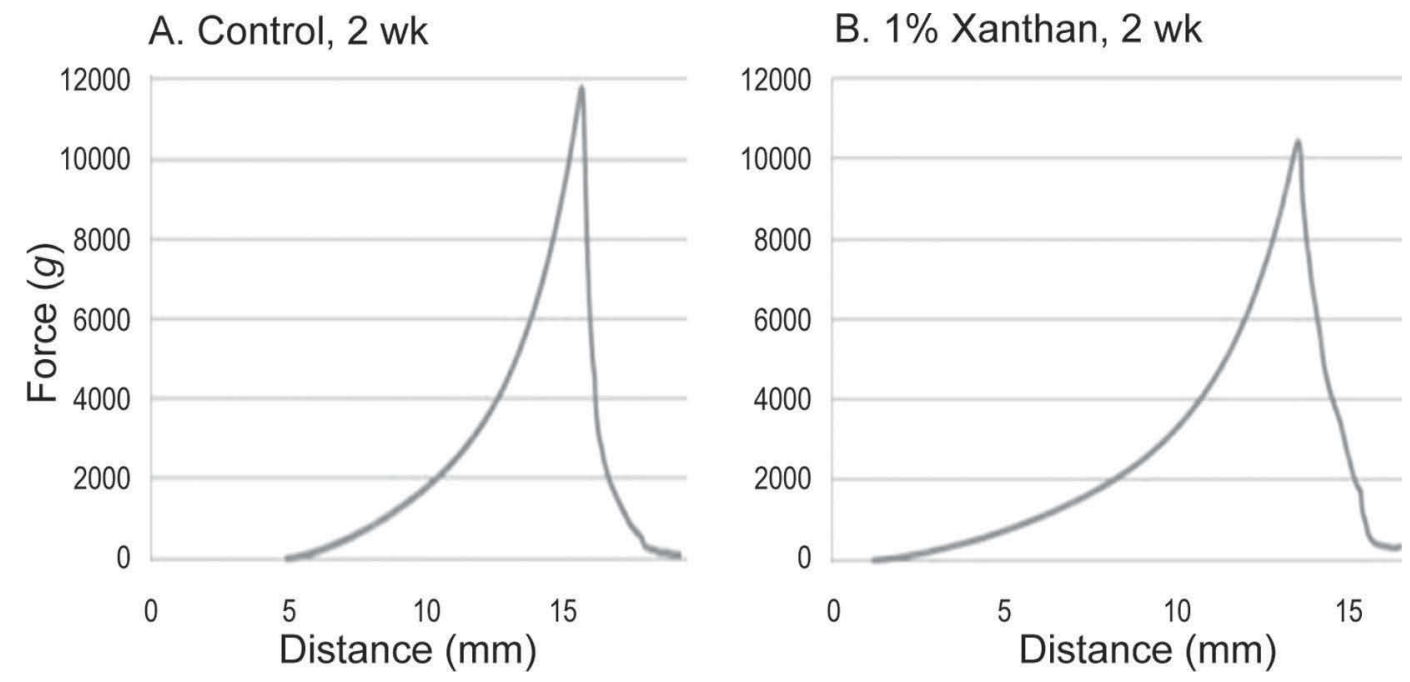

Figure 8. Load-versus-distance curves of (A) control low-fat string cheese and (B) low-fat string cheese with $1 \%$ of a $2 \%$ (wt/wt) slurry of xanthan gum after $2 \mathrm{wk}$ of storage. 

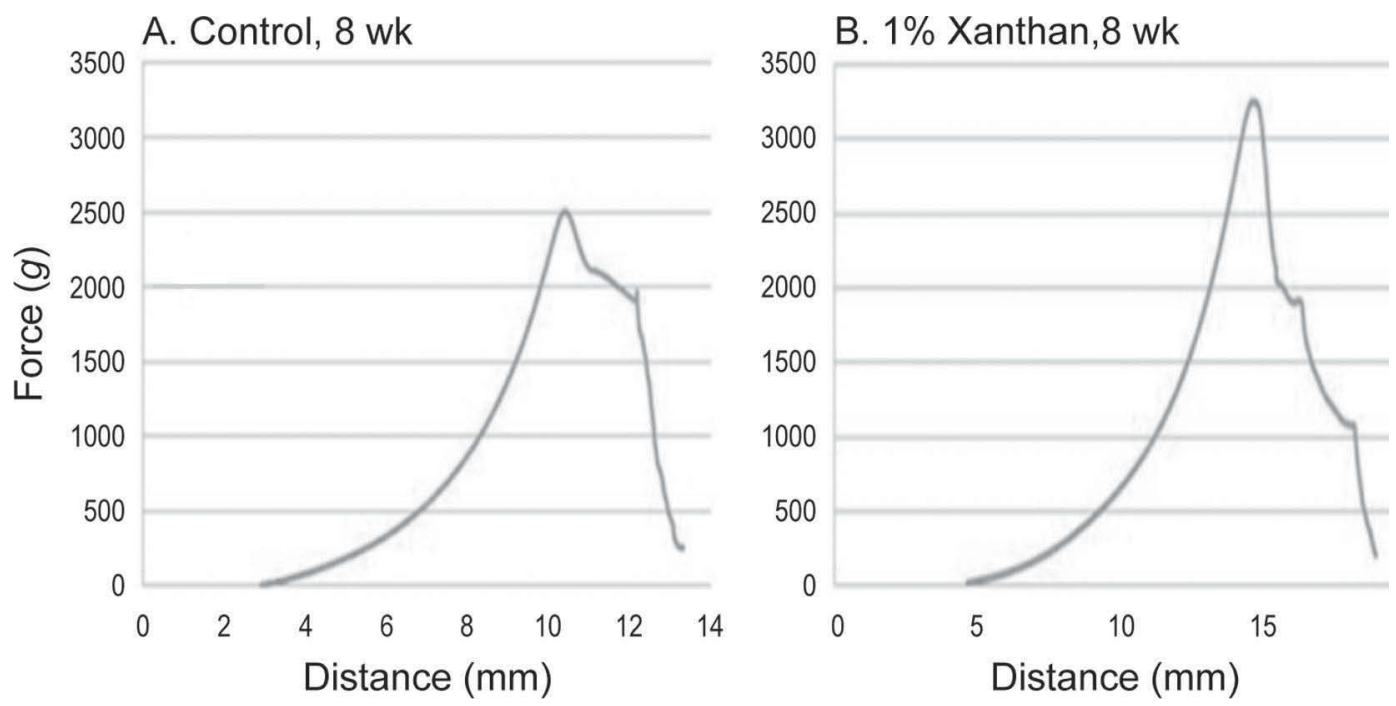

Figure 9. Load-versus-distance curves of (A) control low-fat string cheese and (B) low-fat string cheese with $1 \%$ of a $2 \%$ (wt/wt) slurry of xanthan gum after 8 wk of storage.

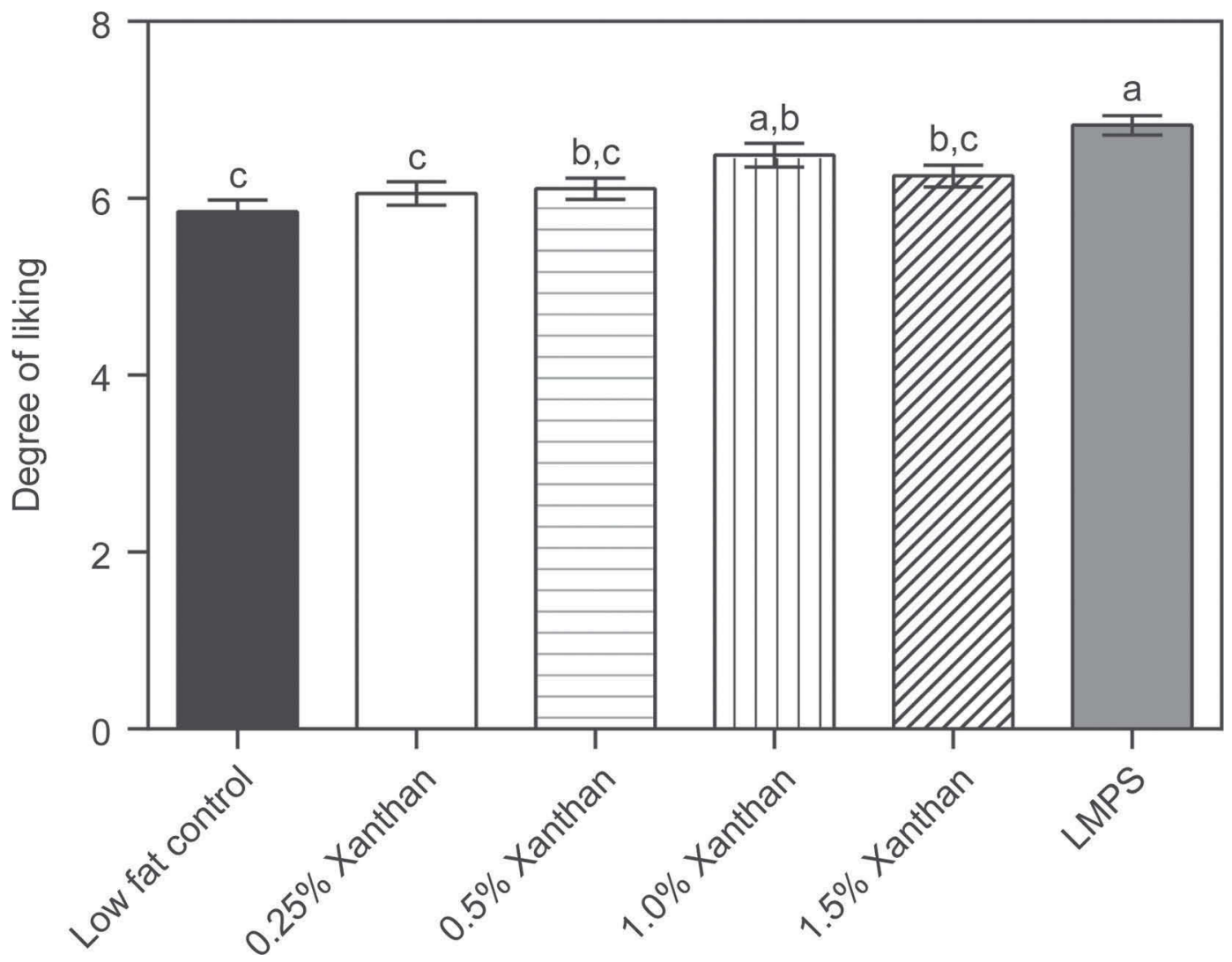

Figure 10. Mean sensory evaluation scores for consumer flavor liking of control low-fat string cheese, low-fat string cheese with $0.25,0.5,1.0$, 1.5, and $2.0 \%$ added xanthan gum slurry compared with a retail-purchased low-moisture part skim (LMPS) mozzarella string cheese after 2 wk of storage at $6^{\circ} \mathrm{C}$. Degree of liking was based on a hedonic scale with $1=$ dislike extremely, $5=$ neither like nor dislike, and $9=$ like extremely. Bars with the same letter $(\mathrm{a}-\mathrm{c})$ were not significantly different. 

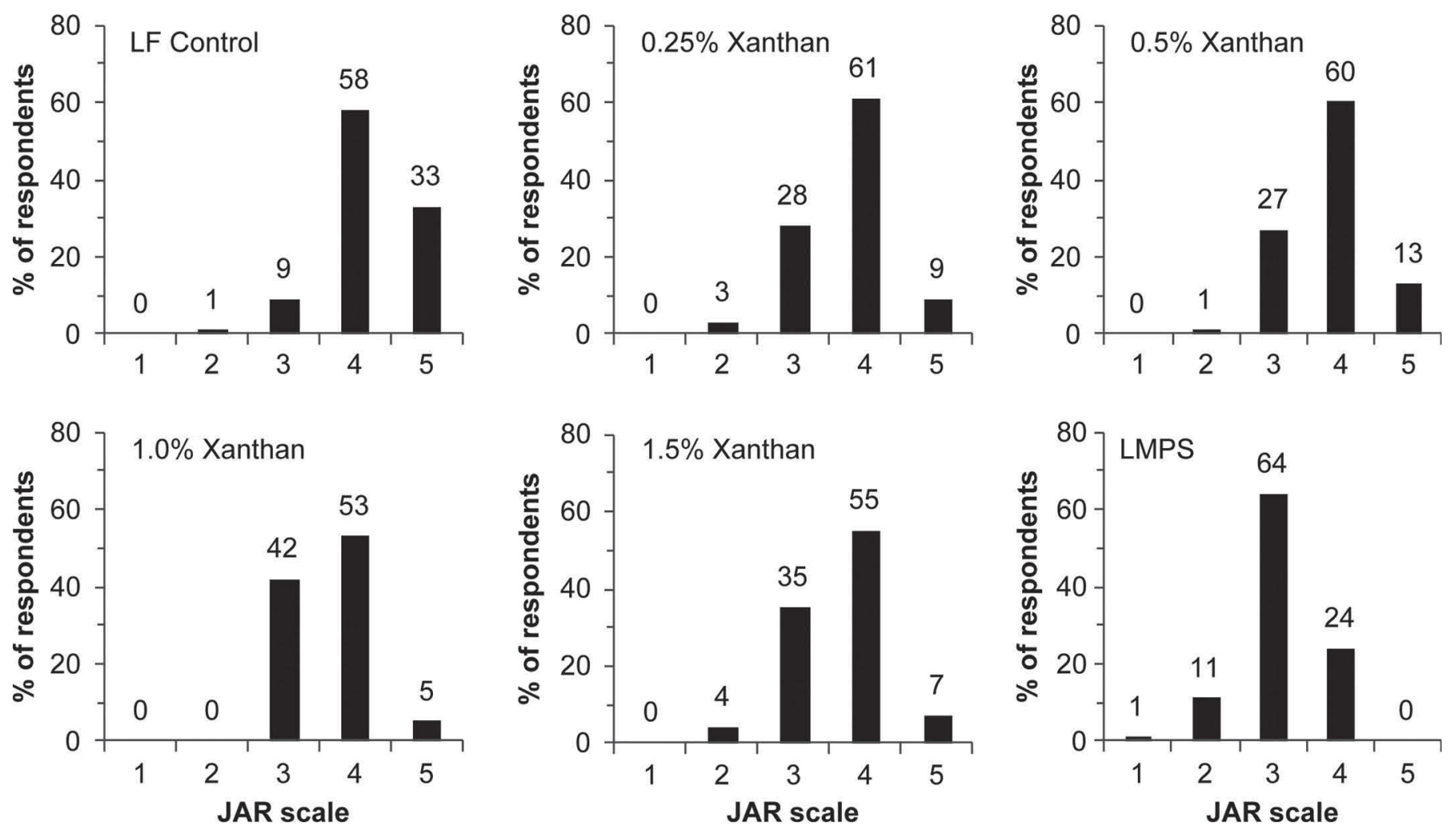

Figure 11. Just-about-right (JAR) evaluation of control low-fat string cheese (LF), low-fat string cheese with $0.25,0.5,1.0,1.5$, and $2.0 \%$ added xanthan gum slurry compared with a retail-purchased low-moisture part skim (LMPS) mozzarella string cheese after 2 wk of storage at $6^{\circ} \mathrm{C}$. The JAR scores are based on a scale in which $1=$ too soft, $2=$ slightly too soft, $3=\mathrm{JAR}, 4=$ slightly too firm, and $5=$ too firm.

LF mozzarella cheese with increased stringiness and had better flavor liking and texture closer to LMPS string scores on consumer JAR texture scores; these LF string cheeses were still rated as being too firm at $2 \mathrm{wk}$ after manufacture and had a tendency to become softer with further storage, but still did not match the LMPS string cheese. A method for measuring stringiness using some type of tensile test or a way to evaluate how the cheese fractures during a penetration or compression test that can be related to stringinesss is needed. The visually observed stringiness of LF cheese with added xanthan gum decreased during 8 wk of storage so that thin strings could no longer be pulled from the cheese. This fusing together of the initially individual protein strands would need to be understood and controlled so as to prevent loss of stringiness during storage.

\section{ACKNOWLEDGMENTS}

We thank Stephen Larsen (Utah State University, retired) for assistance in constructing our pilot plant string cheese extruder and David Irish (Aggie Creamery, Utah State University) for technical assistance in cheese manufacture. We also thank William McManus (Utah
State University, deceased) for his valuable contributions in development of methods for microstructural analysis that were used in this work and his assistance over the past $20 \mathrm{yr}$ in research that has helped us better understand the relationship between chemistry, structure, and functional properties of mozzarella cheese. This research was supported by the Utah Agricultural Experiment Station, Utah State University, and approved as journal paper number 8705 .

\section{REFERENCES}

Barz, R. L., and C. P. Cremer. 1996. Process of making mozzarella cheese. Assignee: Leprino Foods Company. US Patent 5,567,464.

Bhaskaracharya, R. K., and N. P. Shah. 1999. Texture evaluation of commercial mozzarella cheeses. Aust. J. Dairy Technol. 54:37-40.

Brown, K. M., W. R. McManus, and D. J. McMahon. 2012. Starch addition in renneted milk gels: Partitioning between curd and whey and effect on curd syneresis and gel microstructure. J. Dairy Sci. 95:6871-6881.

Caine, W. R., J. L. Aalhus, D. R. Best, M. E. R. Dugan, and L. E. Jeremiah. 2003. Relationship of texture profile analysis and WarnerBratzler shear force with sensory characteristics of beef rib steaks. Meat Sci. 64:333-339.

Corredig, M., N. Sharafbafi, and E. Kristo. 2011. Polysaccharide-protein interactions in dairy matrices, control and design of structures. Food Hydrocoll. 25:1833-1841. 
Duboc, P., and B. Mollet. 2001. Applications of exopolysaccharides in the dairy industry. Int. Dairy J. 11:759-768.

Joshi, N. S., K. Muthukumarappan, and R. I. Dave. 2004. Effect of calcium on microstructure and meltability of part skim Mozzarella cheese. J. Dairy Sci. 87:1975-1985.

Kosikowski, V., and D. Brown. 1969. Application of titanium dioxide to whiten mozzarella cheese. J. Dairy Sci. 52:968-970.

Mayer, M. 2011. String cheese sales increase. Dairy Foods. Accessed Apr. 4, 2013. http://www.dairyfoods.com/articles/87900-stringcheese-sales-increase.

McMahon, D. J., M. C. Alleyne, R. L. Fife, and C. J. Oberg. 1996. Use of fat replacers in low fat mozzarella cheese. J. Dairy Sci. 79:1911-1921.

McMahon, D. J., B. Paulson, and C. J. Oberg. 2005. Influence of calcium, $\mathrm{pH}$, and moisture on protein matrix structure and functionality in direct-acidified nonfat mozzarella cheese. J. Dairy Sci. 88:3754-3763.

McManus, W. R., K. M. Larsen, and D. J. McMahon. 2009. Identification of starch in milk protein gels using confocal microscopy. Micros. Today 17:68-69.

Merrill, R. K., C. J. Oberg, and D. J. McMahon. 1994. A method for manufacturing reduced-fat mozzarella cheese. J. Dairy Sci. $77: 1783-1789$.

Metzger, L. E., D. M. Barbano, and P. S. Kindstedt. 2001. Effect of milk preacidification on low fat Mozzarella cheese: Post-melt chewiness and whiteness. J. Dairy Sci. 84:1357-1366.
Mistry, V. V. 2001. Low fat cheese technology. Int. Dairy J. 11:413422.

Mizuno, R., and J. A. Lucey. 2005. Effects of two types of emulsifying salts on the functionality of nonfat pasta filata cheese. J. Dairy Sci. 88:3411-3425

Mulvaney, S., S. Rong, D. M. Barbano, and J. J. Yun. 1997. Systems analysis of the plastization and extrusion processing of mozzarella cheese. J. Dairy Sci. 80:3030-3039.

Oberg, C. J., W. R. McManus, and D. J. McMahon. 1993. Microstructure of Mozzarella cheese during manufacture. Food Struct. $12: 251-258$.

Ricciardi, A., and F. Clementi. 2000. Exopolysaccharides from lactic acid bacteria: Structure, production and technological applications. Ital. J. Food Sci. 12:23-45.

Rogers, N. R., D. J. McMahon, C. R. Daubert, T. K. Berry, and E. A. Foegeding. 2010. Rheological properties and microstructure of Cheddar cheese made with different fat contents. J. Dairy Sci. 93:4565-4576

Taneya, S., T. Izutsu, T. Kimura, and T. Shioya. 1992. Structure and rheology of string cheese. Food Struct. 11:61-71.

Wadhwani, R., and D. J. McMahon. 2012. Color of low-fat cheese influences flavor perception and consumer liking. J. Dairy Sci. 95:2336-2346.

Wehr, H. M., and J. F. Frank. 2004. Standard Methods for the Examination of Dairy Products. 17th ed. American Public Health Association, Washington, DC. 